This item was submitted to Loughborough's Research Repository by the author.

Items in Figshare are protected by copyright, with all rights reserved, unless otherwise indicated.

\title{
Particle de-agglomeration with an in-line rotor-stator mixer at different solids loadings and viscosities
}

PLEASE CITE THE PUBLISHED VERSION

PUBLISHER

(C) BHR Group

VERSION

AM (Accepted Manuscript)

\section{PUBLISHER STATEMENT}

This work is made available according to the conditions of the Creative Commons Attribution-NonCommercialNoDerivatives 4.0 International (CC BY-NC-ND 4.0) licence. Full details of this licence are available at: https://creativecommons.org/licenses/by-nc-nd/4.0/

\section{LICENCE}

CC BY-NC-ND 4.0

\section{REPOSITORY RECORD}

Padron, Gustavo A., and N. Gul Ozcan-Taskin. 2017. "Particle De-agglomeration with an In-line Rotor-stator Mixer at Different Solids Loadings and Viscosities". figshare. https://hdl.handle.net/2134/26072. 
Particle De-agglomeration with an

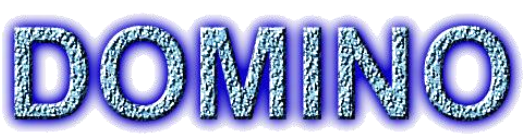

In-Line Rotor-Stator Mixer at

Different Solids Loadings and

Viscosities

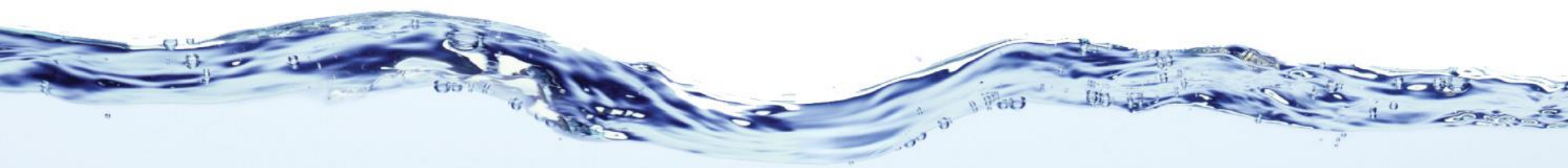

Gustavo A Padron and N. Gül Özcan-Taşkın*

*: Now at Loughborough University, Dept. of Chem. Eng

ISMIP IX - $9^{\text {th }}$ International Symposium on Mixing in Industrial Processes $27^{\text {th }}$ June 2017 


\section{Introduction}

$>$ Rotor-stator mixers are used in the chemical, biochemical, agricultural, cosmetics, and food-processing industries and they are employed in many process operations, including homogenization, dispersion, emulsification and grinding, among others (Atiemo-Obeng \& Calabrese, 2004).

$>$ Despite their widespread use, the understanding of the effect of process variables on the performance of rotor-stator mixers is still highly empirical.

$>$ The work presented looks into the effect of two variables, namely the solids loading and the viscosity of the continuous phase, in a specific process, the deagglomeration of clusters of solid particles, using a fumed silica as a model solid. 


\section{Calorimetry Technique}

$>$ All power input $(P)$ is eventually dissipated as heat in the fluid

$>$ Rig (tank, rotor-stator, lines, connections) insulated to minimise heat losses

$>\mathrm{T}=\mathrm{f}(\mathrm{t})$ measured during $\mathrm{R}-\mathrm{S}$ operation

$>P=m C_{P} \frac{\Delta T}{t}$

$>$ Fluids:

- water

- $60 \%$ wt Aqueous glycerol solution

- $84 \% w t$ Aqueous glycerol solution

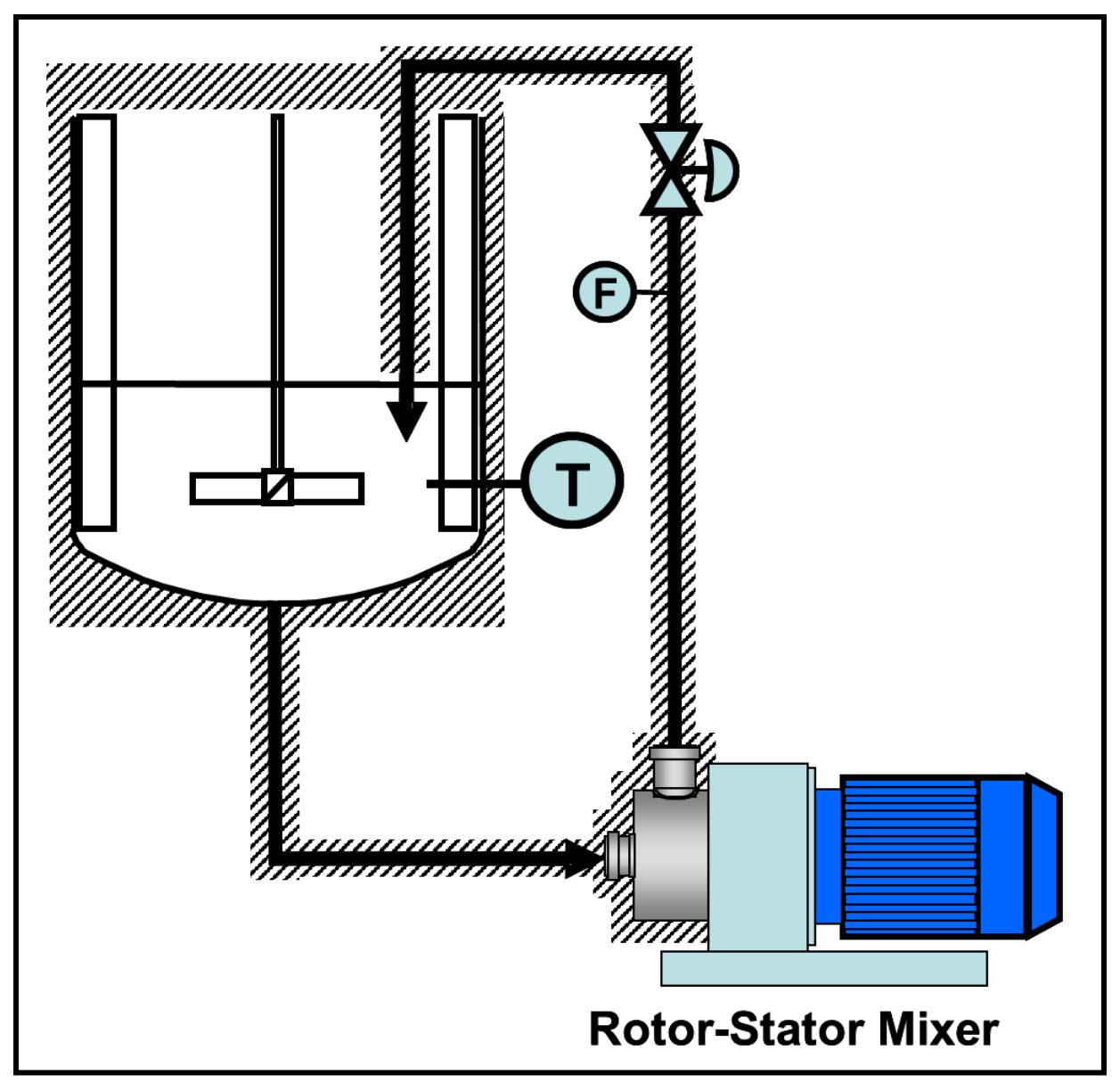




\section{Power Number vs Reynolds \& Flow Number}

Özcan-Taşkın et al. (2011):

$$
\begin{gathered}
P=P o_{1} \rho N^{3} D^{5} \\
+P o_{2} \rho N^{2} D^{2} Q
\end{gathered}
$$

Power number:

$$
\begin{aligned}
P o & =\frac{P}{\rho N^{3} D^{5}} \\
& =P o_{1}+P o_{2} F l
\end{aligned}
$$

$F l=\frac{Q}{N D^{3}} \quad R e=\frac{\rho N D^{2}}{\mu}$

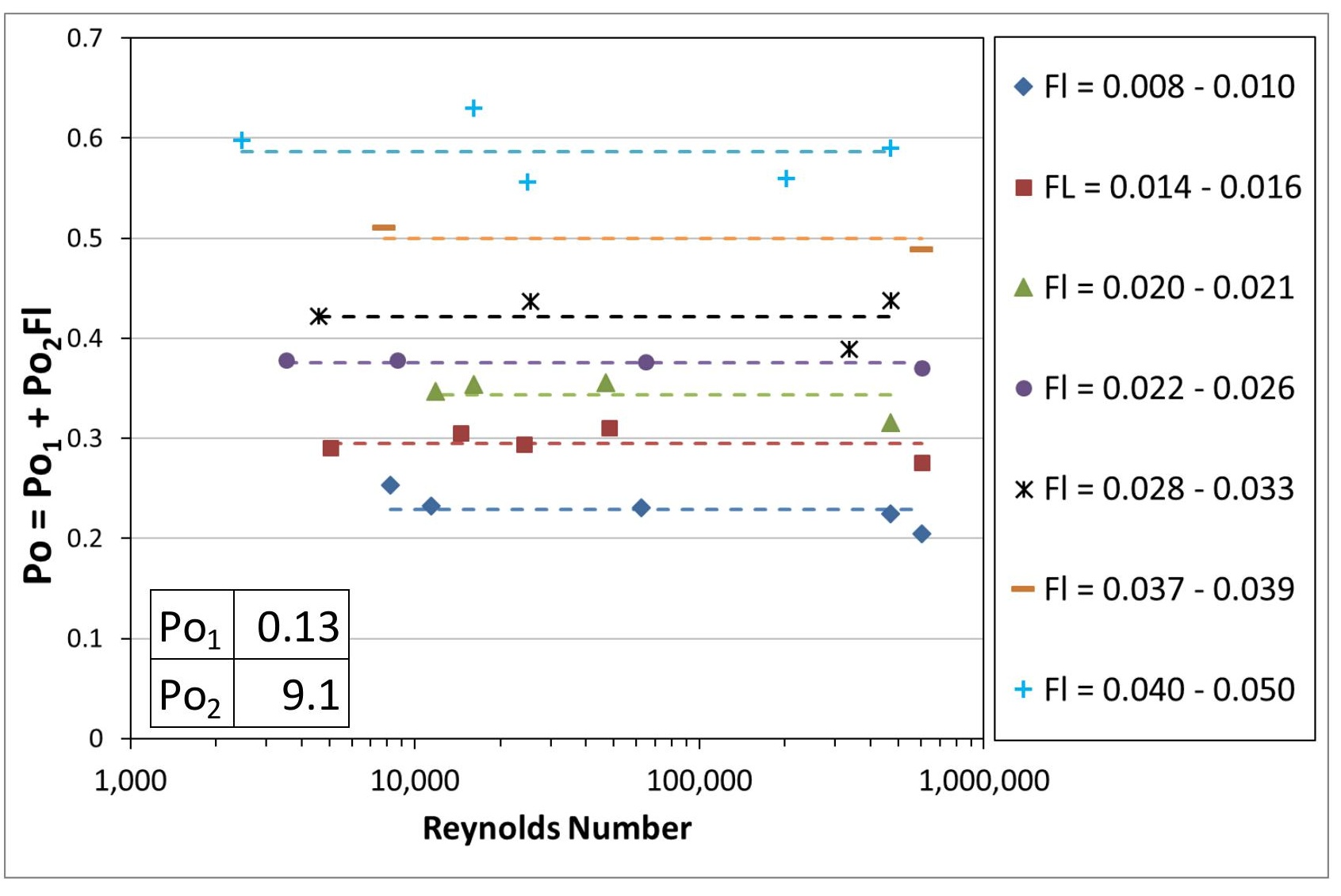

$>$ For a given $\mathrm{Fl}, \mathrm{Po}$ is constant over the whole Re range, i.e. the flow within the rotor-stator is turbulent. 


\section{Experimental Set Up - Break-Up Experiments}

$>$ Silverson 150/250MS rotor-stator

$>$ Rotor $\left(D_{\text {out }}=63.8 \mathrm{~mm}\right)$

$>$ EMSC Stator

$>$ Shear Gap $(\delta)=0.15 \mathrm{~mm}$

$>$ Rotor speeds: 7,950 rpm

$>$ Flow rate: $0.6 \mathrm{l} / \mathrm{s}$

Fl: 0.017

$>\mathrm{P} / \mathrm{m}: 7.1 \mathrm{~W} / \mathrm{kg}$ (total mass)

$>$ Total suspension volume $=0.1 \mathrm{~m}^{3}$

$>$ Fumed silica concentrations: 1, 10 and 15\%wt

$>$ Glycerol concentrations (1\%wt silica): 60 \& 85\%wt

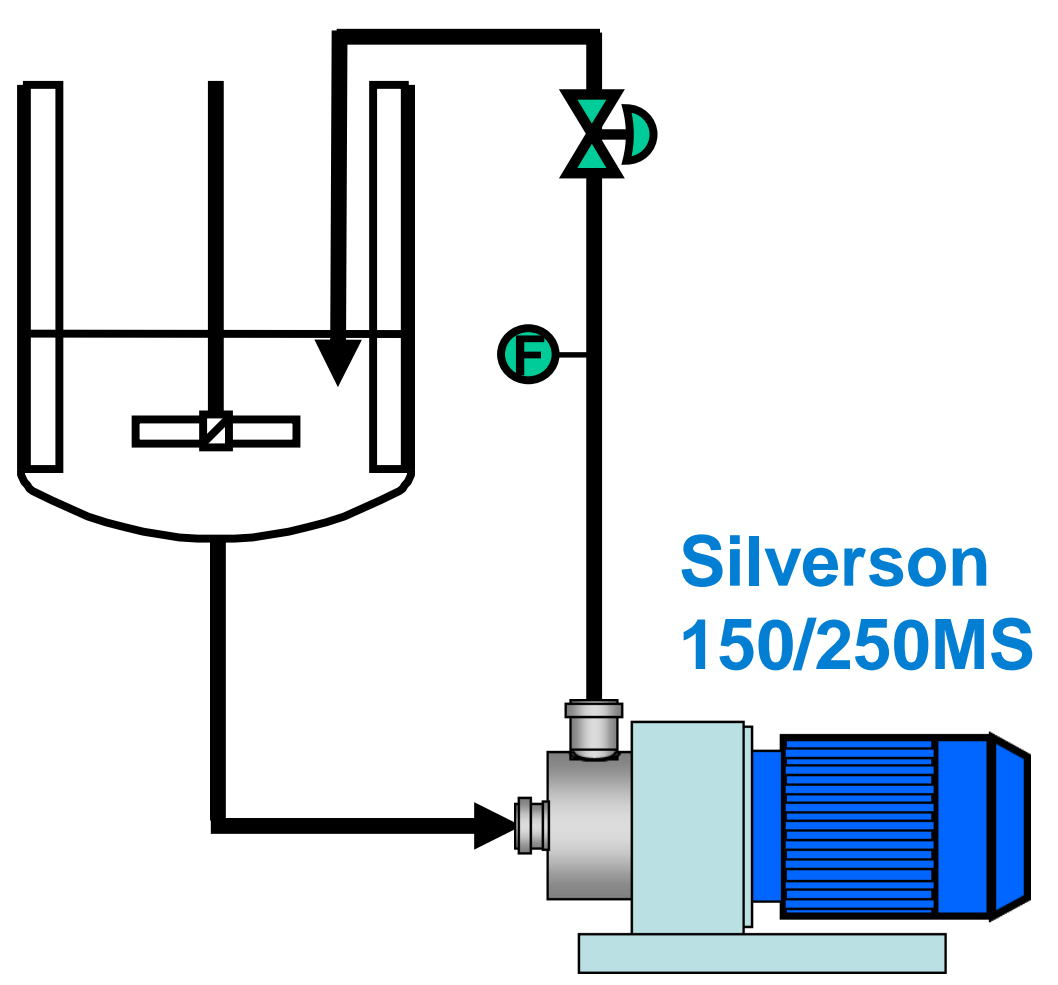




\section{Dispersion Rheology}

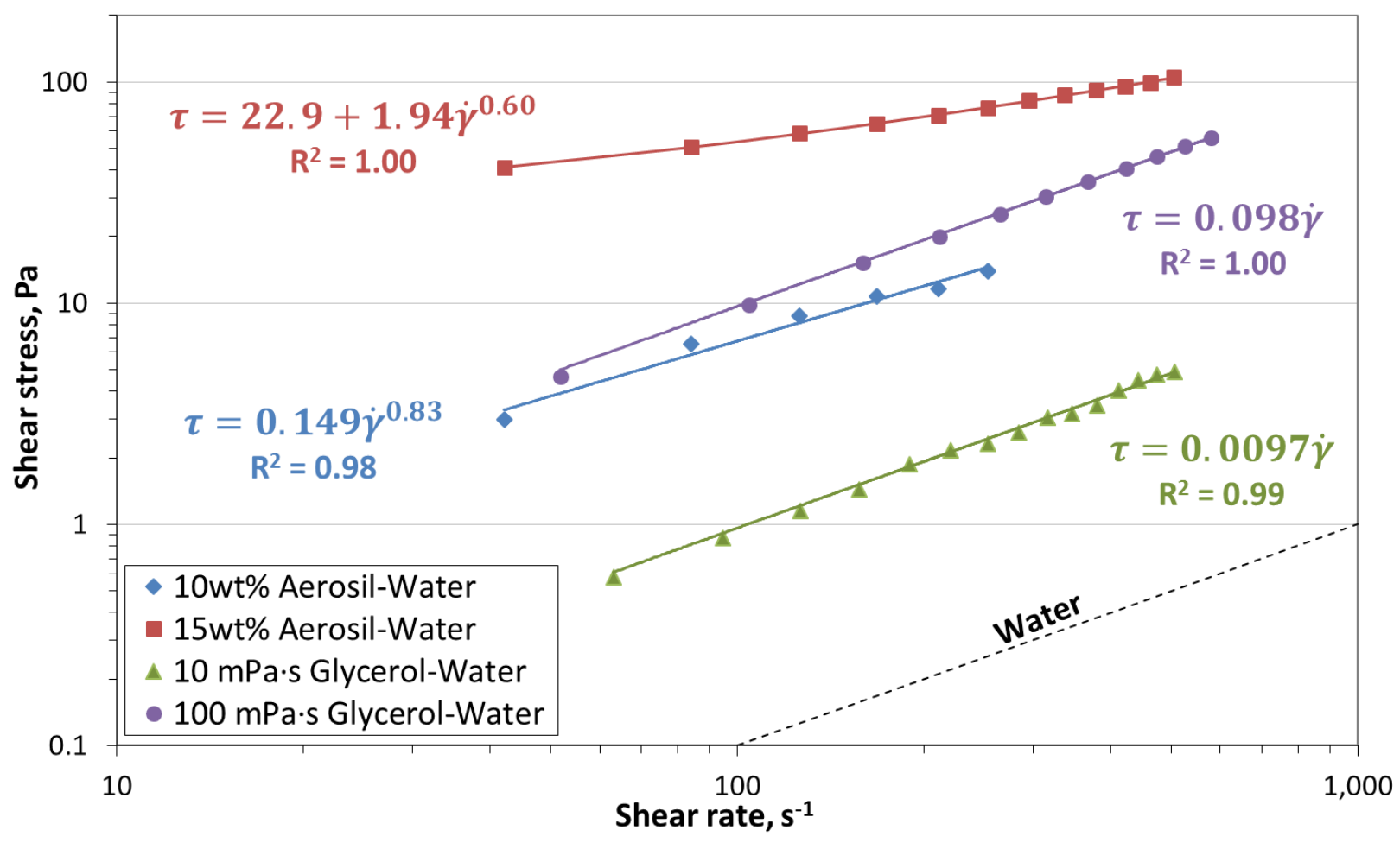

$>$ With $1 \%$ wt Aerosil in water, the viscosity was "water-like" (not measured)

$>$ At 10 and 15\%wt Aerosil, the dispersions' viscosity is considerable higher and they become significantly non-Newtonian

$>$ Glycerol solutions: no significant increase after 1\%wt Aerosil addition. 
Break Up Tests - Particle Size Distribution Evolution

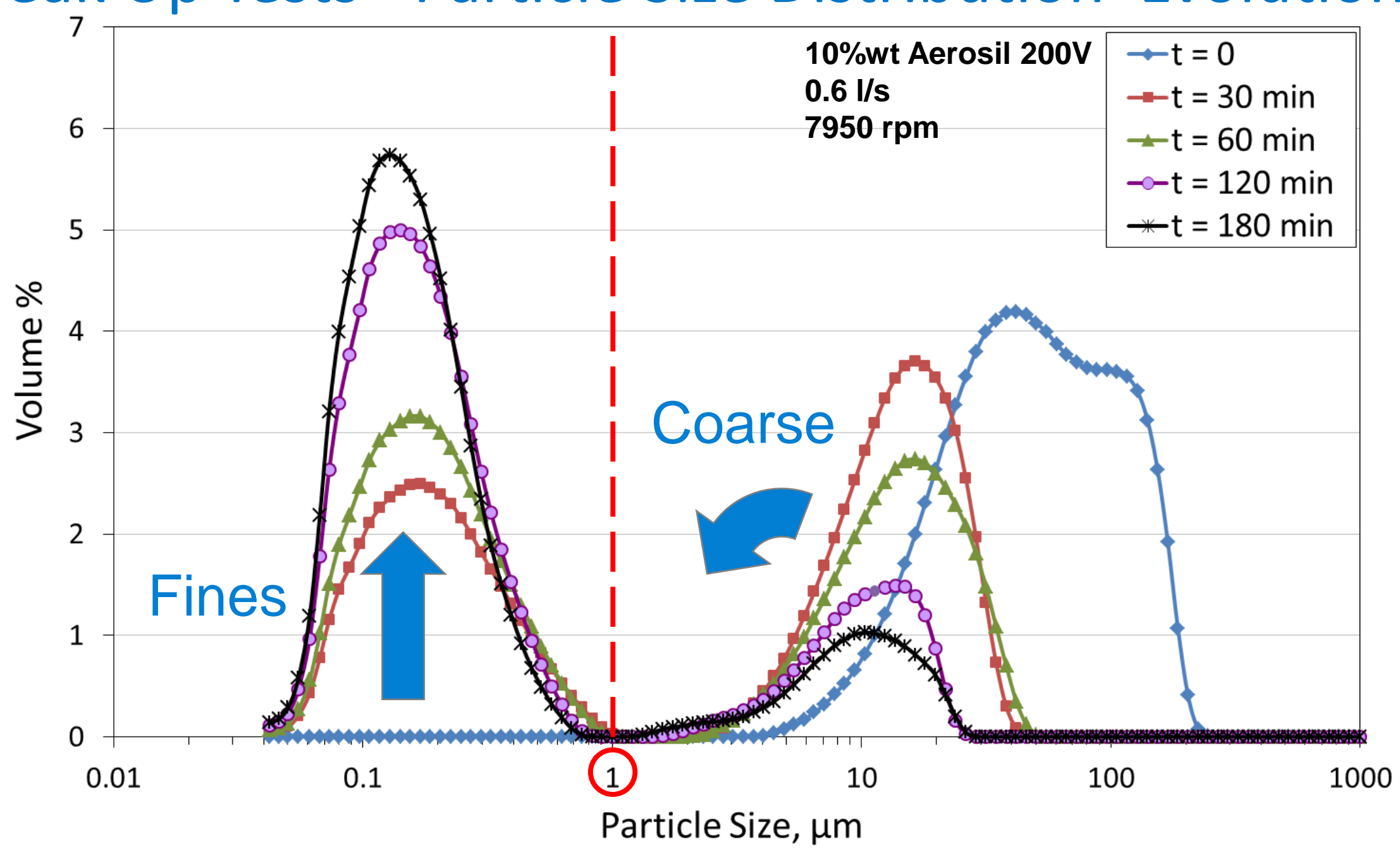

$>$ Break up rate quantified as the rate at which fines volume fraction increases 


\section{Fines Generation Rate}

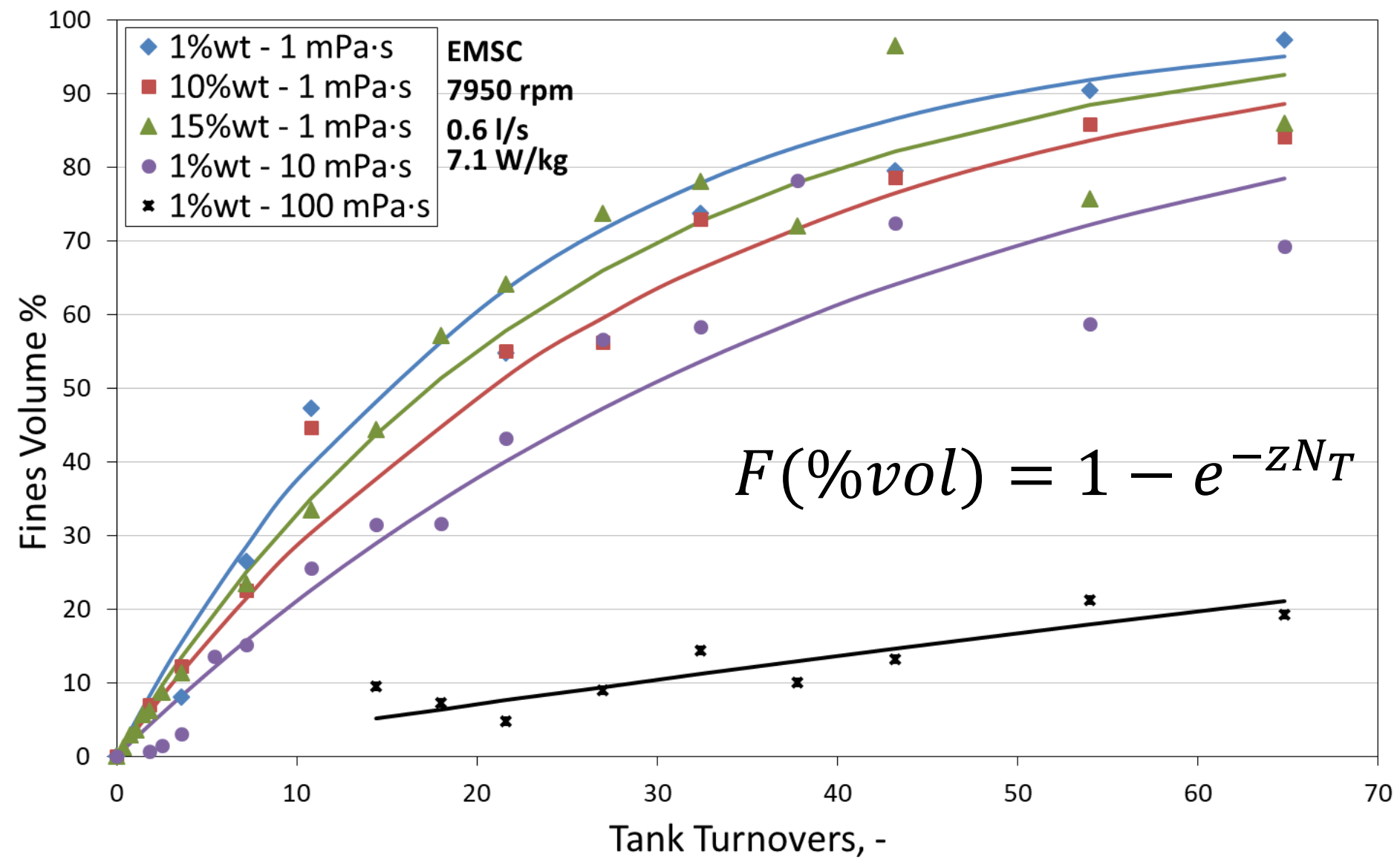

$>$ Small difference and no trend with the Aerosil-Water dispersions

$>$ In Glycerol/Water solutions, the break up rate is reduced as the viscosity of the solution increases 


\section{Fines Generation Rate}

\section{BHR Group}

EXPERTS IN FLUID ENGINEERING

\begin{tabular}{|l|c|c|c|c|c|c|c|c|c|}
\cline { 2 - 9 } \multicolumn{1}{c|}{$\dot{\gamma}_{N}=\frac{v_{t i p}}{\delta}$} & $\mu_{(\mathrm{a})}(\mathrm{N})$ & $\mu_{(\mathrm{a})}(\mathrm{K})$ & $\operatorname{Re}(\mathrm{N})$ & $\operatorname{Re}(\mathrm{K})$ & $\mathbf{Z}$ & $\mu_{\mathrm{C}}$ & $\mathrm{d}_{32}, \mathrm{t}=0$ & $\eta_{\mathrm{K}}$ & $\mathrm{d}_{32, \mathrm{t}=0} / \eta_{\mathrm{K}}$ \\
$\mathrm{mPa} \cdot \mathrm{s}$ & $\mathrm{mPa} \cdot \mathrm{s}$ & - & - & - & $\mathrm{mPa} \cdot \mathrm{s}$ & $\mu \mathrm{m}$ & $\mu \mathrm{m}$ & - \\
\hline $1 \%$ wt A-W & 1 & 1 & 534,273 & 534,273 & $\mathbf{0 . 0 4 7}$ & 1 & 28.9 & 19.4 & 1.49 \\
$10 \%$ wt A-W & 18.6 & 38.3 & 32,131 & 15,618 & $\mathbf{0 . 0 3 4}$ & 1 & 36.1 & 19.4 & 1.86 \\
$15 \%$ wt A-W & 15.8 & 92.0 & 39,899 & 6,850 & $\mathbf{0 . 0 4 0}$ & 1 & 38.1 & 19.4 & 1.97 \\
\hline $1 \%$ wt A-10 mPa.s G-W & 9.7 & 9.7 & 63,418 & 63,418 & $\mathbf{0 . 0 2 4}$ & 9.7 & 38.0 & 95.8 & 0.40 \\
$1 \%$ wt A-100 mPa.s G-W & 98 & 98 & 6,661 & 6,661 & $\mathbf{0 . 0 0 3 7}$ & 98 & 44.1 & 519.2 & 0.08 \\
\hline
\end{tabular}

Flow within the rotor-stator is turbulent under $\dot{\gamma}_{K}=\left(\frac{\varepsilon}{v_{K}}\right)^{1 / 2} \quad \eta_{K}=\left(\frac{v^{3}}{\varepsilon_{\text {mean }}}\right)^{1 / 4}$ all conditions (based on power draw data)

$>$ In the A-W dispersions, the flow around the particles is given by the continuous phase properties and the initial particle size is greater than the Kolmogorov scale $\left(\eta_{\kappa}\right)$

$>$ In A-G/W dispersions, $d_{32(t=0)}<\eta_{K}$, the flow around the particles is viscous and this reduces the break up rate $(Z)$

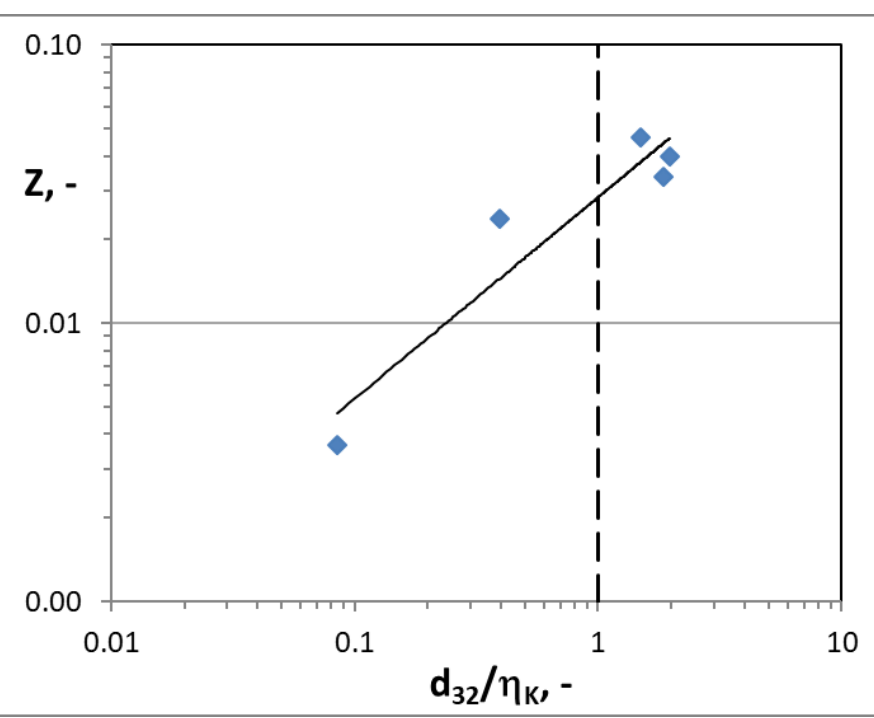

Slide 10 


\section{Effect of Solids Concentration}

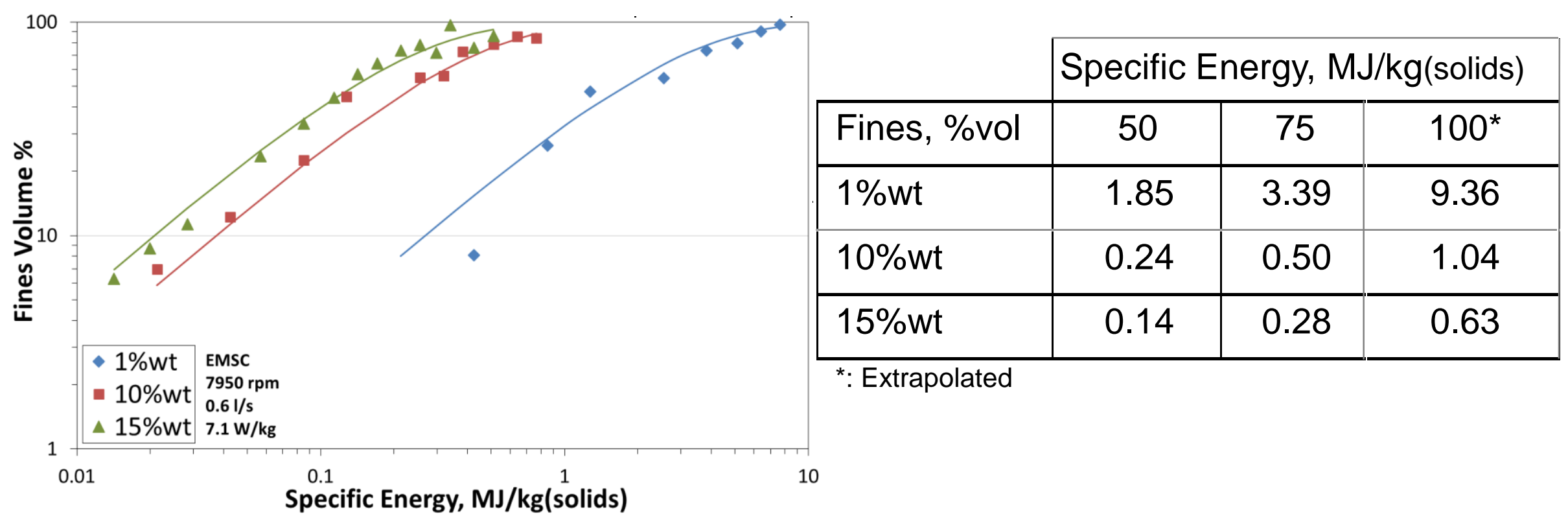

$>$ The energy required per unit mass of solids to achieve a given fines fraction is, at least one order of magnitude higher at $1 \%$ wt than at $15 \%$ wt. At $10 \%$ wt is $60-80 \%$ higher than at $15 \% w t$.

$>$ Therefore, it is more energy efficient to operate at higher solids concentrations (and then dilute as necessary) 


\section{Conclusions}

$>$ The power draw of an in-line rotor-stator has been characterised at Reynolds numbers between 2,400 and 600,000. The results show that the flow in the R-S is turbulent within this range.

$>$ Solids concentration has an important effect on the rheology of the dispersions.

$>$ The break up rate (fines generation rate) depends on the flow conditions around the particle, not the overall dispersion rheology. The initial mean particle size and the Kolmogorov microscale (mean power input) can be used to determine these flow conditions.

$>$ It is more energy efficient to operate at higher solids concentration (as long as the flow with the rotor-stator is still turbulent, because a larger amount of solids is processed in a given time and, therefore, the energy expenditure per unit mass of solids is lower. 
Acknowledgements

$>$ Members of the DOMINO Consortium http://domino.bhrgroup.com/

$>$ Mr Chris Hampson 


\title{
End of Presentation
}

\author{
Questions?
}




\section{References}

$>$ Atiemo-Obeng, V. A., \& Calabrese, R. V. (2004). Rotor-stator mixing devices. Handbook of industrial mixing: Science and practice, 479-505.

D Özcan-Taşkın, G., Kubicki, D., \& Padron, G. (2011). Power and flow characteristics of three rotor-stator heads. The Canadian Journal of Chemical Engineering, 89(5), 1005-1017 


\section{Power Number - GPDH+SQHS vs EMSC}

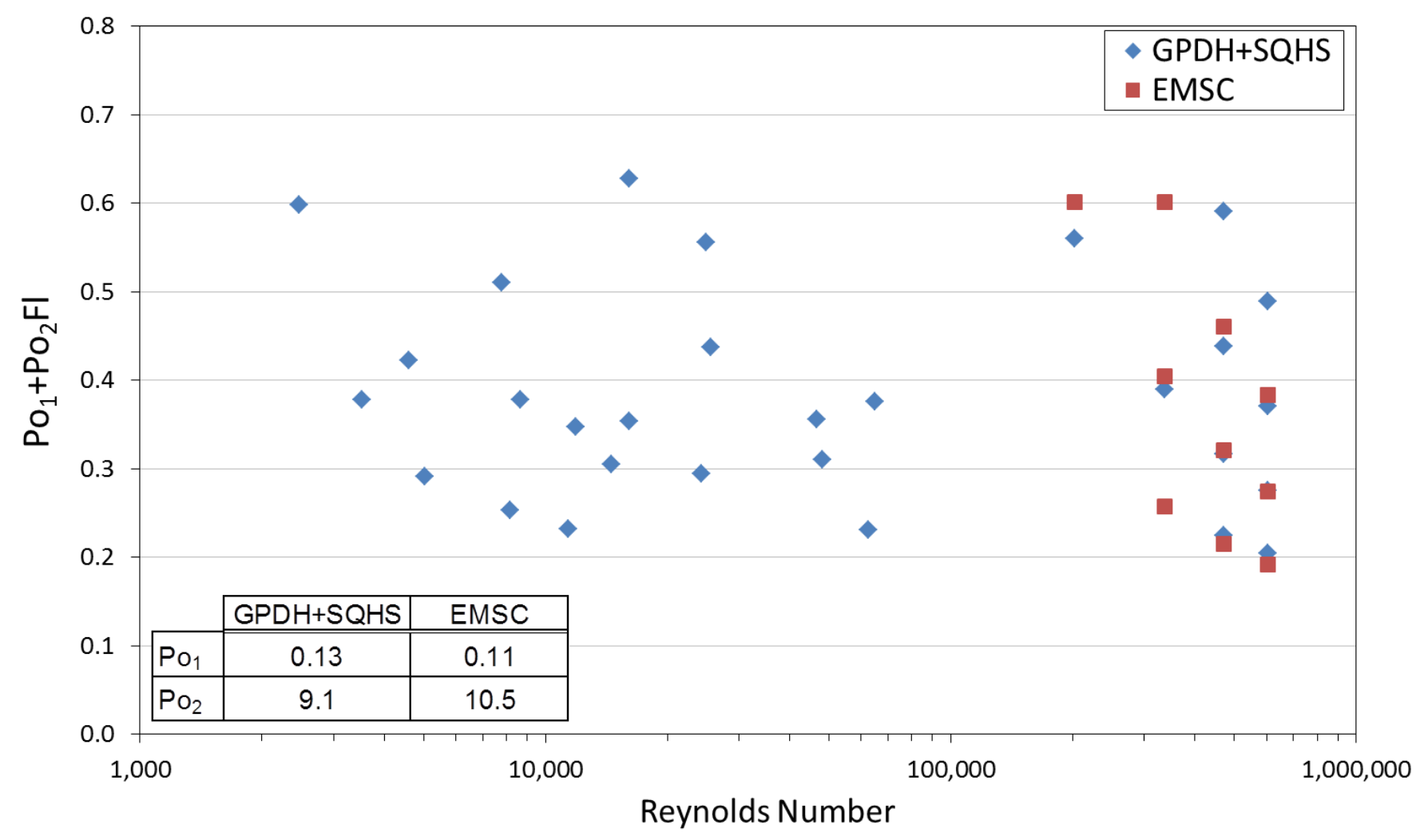

D The power draw tests with higher viscosities was only carried out with the $\mathrm{GPDH}+\mathrm{SQHS}$. Given the similarities between the $\mathrm{Po}_{1}$ and $\mathrm{Po}_{2}$ values and of the results in water of the two geometries, it stands to reason that the flow is also turbulent when the EMSC is used under the same conditions 


\section{Dispersion Rheology - Vane \& Basket}

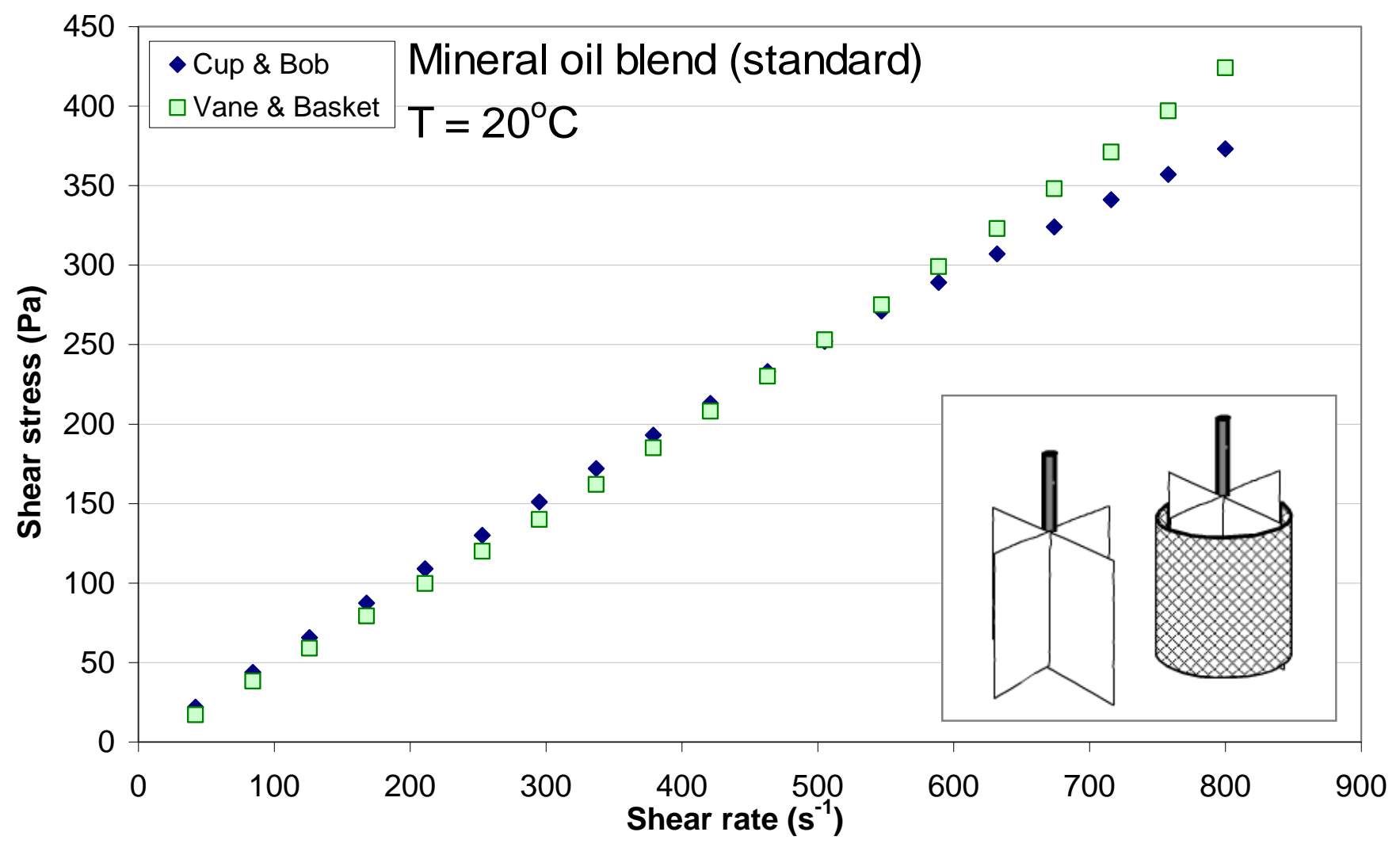

$>$ The vane and basket geometry's results were validated by measuring the flow curve of a Newtonian oil standard with it and with the cup and bob geometry. 


\section{Particle Break Up Mechanisms}

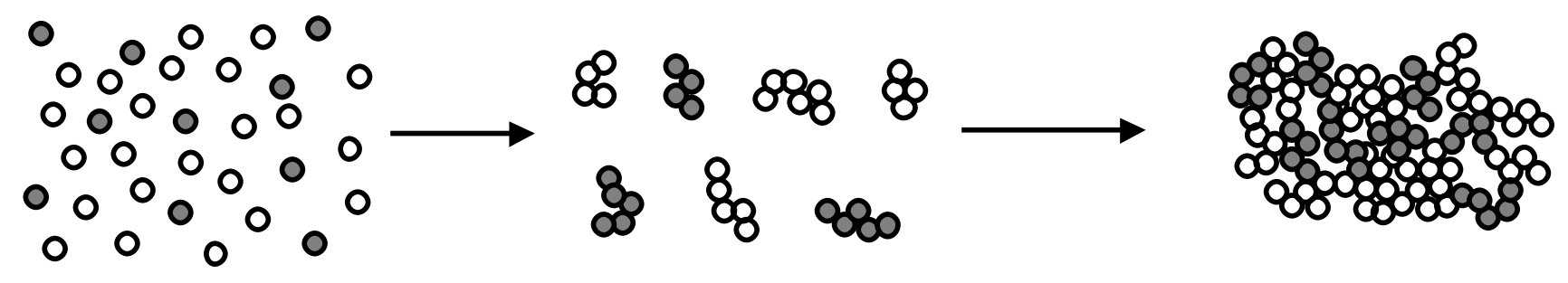

Primary Particles Aggregates Agglomerates

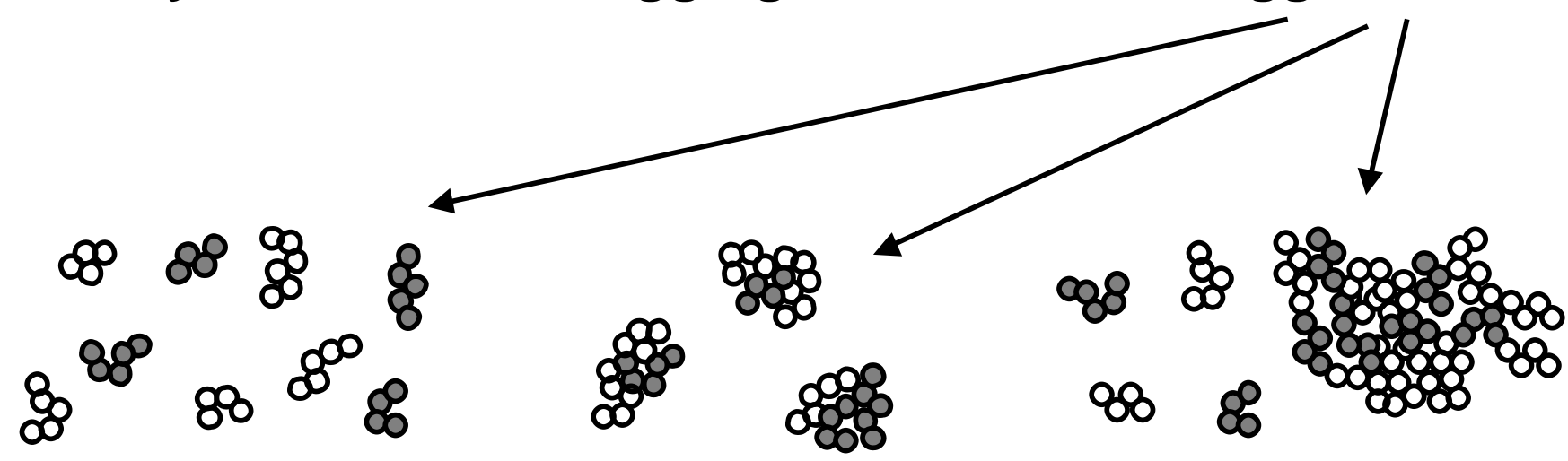

Shattering

Rupture

Erosion

$>$ Rwei, Manas-Zlocsower and Feke (1990), Redner (1990), Ottino et al (2000)

$>$ Different relative energy (to agglomerate strength) levels required: 


\section{BHR Group}

\section{Materials}

$>$ All experiments were carried out with Aerosil $^{\circledR} 200 \mathrm{~V}$ in distilled water or glycerol aqueous solutions

$>$ Aerosil 200V is a fumed hydrophilic silica manufactured by Evonik Industries

$>$ The primary particle is $12 \mathrm{~nm}$ (according to manufacturer)

$>$ Electron microscopy studies have shown that the smallest aggregates are of the order of $100 \mathrm{~nm}$

$>$ PSD measured by light scattering (Beckman Coulter LS230) using a refractive index of $1.46+0.1 \mathrm{i}$

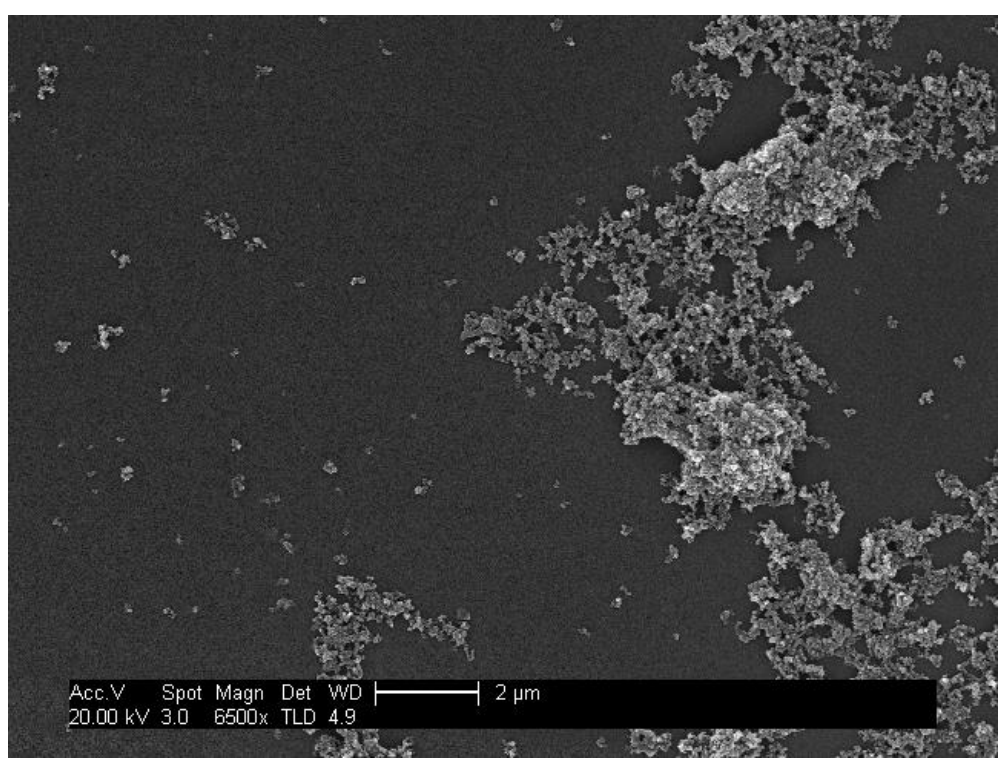

8

8

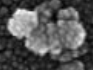

3 
$\mathrm{d}_{32}\left(\mathrm{~N}_{\mathrm{T}}\right) / \eta_{10} \mathrm{vs} \mathrm{N}_{\mathrm{T}}$

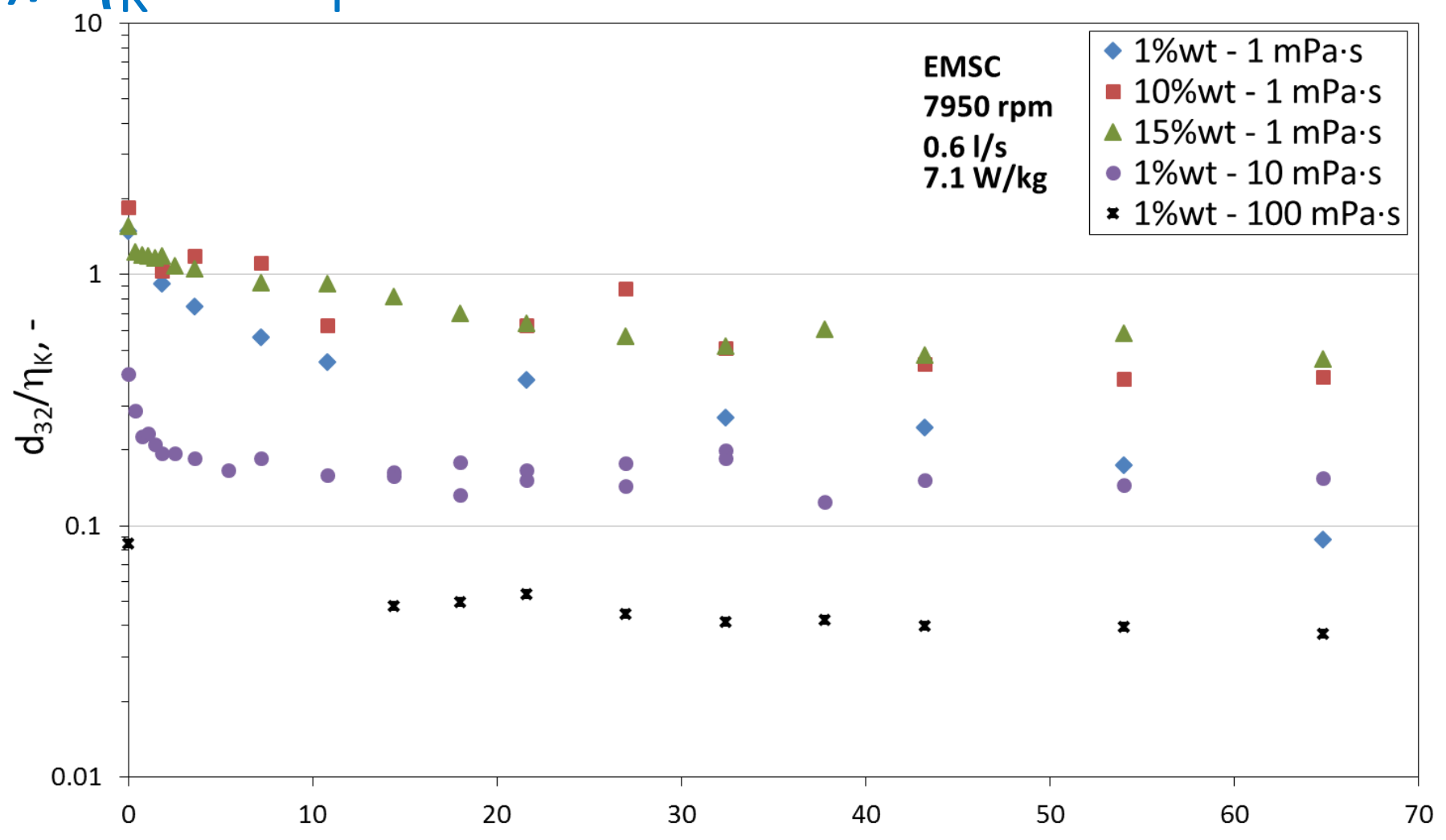

A-W: particle size eventually becomes Smankller than $\eta_{K}$, but at least for the first $\sim 10$ turnovers (fastest break up) it is at least $O\left(\eta_{K}\right)$.

$>$ A-G/W: particle size always smaller (up two orders of magnitude) than $\eta_{\mathrm{K}}$ 